the diagnosis of whooping cough was confirmed by isolating $B$. pertussis the complement fixation test seemed rather more sensitive than the agglutination test in detecting rising antibody titres. Thus, when the complement fixation technique is convenient and practical, as in virus laboratories where paired sera from children with respiratory infections are tested against a battery of complement fixation antigens, a $B$. pertussis antigen could be useful.

We found that the age of the patient was of considerable importance in relation to both $B$. pertussis isolations and serological responses. Under 6 months of age isolation of $B$. pertussis was much commoner than positive serological findings; over 1 year of age serological tests were more often positive than were cultures. Our study suggests that two agerelated factors were involved in this difference-namely, a poor or delayed antibody response by the young infant as has been previously reported in other respiratory infections (Grist, 1957; Chanock et al., 1961; Ross et al., 1964) and the low proportion of children under 6 months of age who had been fully immunized against $B$. pertussis. In some children previous immunization appeared to have suppressed growth of $B$. pertussis in the nasopharynx but not the serological response.

The preponderance of serotype 1,3 in both immunized and unimmunized patients is in keeping with previous findings reported by Preston $(1963,1965)$ and by the Public Health Laboratory Service Whooping Cough Committee and Working Party (1969). These reports indicated that the efficacy of much of the pertussis vaccine in use for some years before 1968 required improvement. Though since 1964 all manufacturers in the United Kingdom have included strains 1,3 in their B. pertussis vaccines (British Medical fournal, 1969) it would appear from the clinical and bacteriological findings of the present study that current whooping cough vaccines are still not adequately protective against strain 1,3.

We wish to thank Mr. K. Begg, Mr. S. McMichael, and Mr. D. Veitch, for valuable technical help; many general practitioners and medical officers of health for immunization particulars; and clinical colleagues for collection of sera.

\section{REFERENCES}

Bordet, J., and Gengou, O. (1906). Annales de l'Institut Pasteur, 20, 731. Bordet, J., and Gengou, O. (1907). Annales de l'Institut Pasteur, 21, 720. Cited by W'ilson and Miles (1964)

Bradstreet, C. M. P., and Taylor, C. E. D. (1962). Monthly Bulletin of the Ministry of Health and the Public Health Laboratory Service, 21, 96.

British Medical fournal, 1969, 4, 316.

Buck, A. A., and Gart, J. J. (1966). American fournal of Epidemiology, 83, 586.

Casey, H. L. (1965). U.S. Public Health Monograph, No. 74.

Chanock, R. M., et al. (1961). Fournal of the American Medical Association, $176,647$.

Cruickshank, R. (editor) (1965). Medical Microbiology, 11 th edn., p. 766 Edinburgh, Livingstone.

Donald, A. B. (1938). British Medical fournal, 2, 613

Evans, D. G., and Maitland, H. B. (1939a). Fournal of Pathology and Bacteriology, 48, 465.

Evans, D. G., and Maitland, H. B. (1939b). Journal of Pathology and Bacteriology, 48, 468.

Grist, N. R. (1957). Scottish Medical fournal, 2, 249.

Grist, N. R. (1957). Scottish Medical fournal, 2, 249. E. J. (1966). Diagnostic Methods in Clinical Virology. Oxford, Blackwell.

Preston, N. W. (1963). British Medical Fournal, 2, 724.

Preston, N. W. (1965). British Medical fournal, 2, 11

Price, I. N. O. (1932). Fournal of Pathology and Bacteriology, 35, 635.

Public Health Laboratory Service Report (1969). British Medical fournal, 4, 329.

Ross, C. A. C., Stott, E. J., McMichael, S., and Crowther, I. A. (1964). Archiv für die gesamte Virusforschung, 14, 553 .

Wilson, Sir G. S., and Miles, A. A. (1964). Topley and Wilson's Principles of Bacteriology and Immunity, 5 th edn., vol. 2, p. 2008. London, Arnold.

\title{
Outcome of Recent Thromboembolic Occlusions of Limb Arteries Treated with Streptokinase
}

\author{
A. AMERY,* M.D. ; W. DELOOF, $†$ M.D. ; J. VERMYLEN, $\ddagger$ M.D. ; M. VERSTRAETE, $₫$ M.D.
}

$S^{\text {un }}$ ummary: All our patients with a recent thromboembolic occlusion of limb arteries treated with streptokinase have been reviewed retrospectively. Clearing of the main artery, as judged by arteriography or reappearance of arterial pulsations, occurred more often when treatment was started early. If only patients with an iliac, femoral, or popliteal artery occlusion are considered, those who received a lower initial dose had a significantly higher clearing rate and a significantly lower mortality than those who received a high initial dose $(500,000$ units of streptokinase or more). Therefore an initial standard dose of $1,200,000$ units of streptokinase is no longer recommended in these conditions, and even an individually titrated initial dose of more than half a million units could be hazardous. If no neurological abnormalities were present on admission amputation was never necessary, even if clearing of the main artery did not occur. If there was sensory loss of at least part of a limb, amputation was avoided only if the pulsations returned in at least one artery of hand or foot.

\footnotetext{
* Lecturer.

† Assistant.

Instructor.

Laboratory of Coagulation, Department of Medicine, University of Louvain,
} Louvain, Belgium.
During the administration of streptokinase in patients with
a recent thromboembolic occlusion of a limb artery, patency
of the main artery can be restored (Fletcher et al., 1959;
Gross et al., 1960; Kahn et al., 1961; Cotton et al., 1962; Nils-
son and Olow, 1962; McNicol et al., 1963; Salmon et al.,
1963 ; Schmutzler, 1963, 1968; Verstraete et al., 1963; Winckel-
mann et al., 1963; Marchal et al., 1964; Haan and Tilsner,
1965; Hess, 1967). Nevertheless, neither the incidence of
spontaneous disobstruction nor the optimal dose and duration
of streptokinase therapy have yet been established. Further-
more, no controlled study is available that compares the
value of streptokinase treatment with other current therapeu-
tic regimens.
We have shown (Verstraete et al., 1966), on the basis of
arteriographic studies, that in these patients patency of the
main artery can be obtained after administration of
streptokinase according to the following standard dosage
scheme: a set initial dose of $1,250,000$ units and a mainten-
ance dose of 100,000 units/hour for 72 hours. Since then
more patients have been treated by this method. The aim of
this paper is to describe the outcome in patients in whom recent thromboembolic occlusion of a limb artery was treated with streptokinase, and to compare the results obtained using 
a high initial dose with those obtained with a moderate initial dose. Biochemical changes in the plasma during the different types of streptokinase administration have been reported elsewhere (Amery, 1969).

\section{Methods}

\section{(1) Patient Selection and General Condition}

Eighty-five patients treated with streptokinase for thromboembolic occlusion of a limb artery or the abdominal aorta have been studied retrospectively; some have already been reported (Verstraete et al., 1963, 1964, 1966). The patients were divided into three groups according to their general condition at admission, using the following criteria :

Grade 1. Good general condition: the patient was ambulant until just before the acute episode and the general condition on admission was good-that is, one of the criteria mentioned below was not fulfilled.

Grade 2. Bad general condition: patients with heart failure, with or without auricular fibrillation, severe angina, or recent myocardial infarction, oxygen desaturation of the arterial blood at rest, recent cerebrovascular accident.

Grade 3. Very bad general condition (likely to die): oliguria, intractable heart failure, cachexia by carcinomatosis, coma, etc.

\section{(2) Streptokinase Dosage and Control}

Before 1965 the initial dose was calculated from the results of the streptokinase reactivity test (Amery et al., 1963); the patients then received about 1,200,000 units during each subsequent 12 -hour period. More recently the standard dosage scheme mentioned above has been followed. The duration of streptokinase administration depended on the clinical condition: if clearing occurred treatment was interrupted; if no clearing was noted the infusion was continued for about 72 nours.

\section{(3) Clinical Evaluation}

The following criteria are used for the clinical evaluation:

(a) Type of Occlusion.-The distinction was made between embolus and thrombus on clinical grounds. The thromboembolic occlusion was considered to be due to a thrombosis when no source for emboli was present (no recent myocardial infarction, no atrial fibrillation, etc.) and when, before the acute episode, intermittent claudication which was not due to previous emboli was present. The occlusion was considered to be embolic when there were no signs of arterial insufficiency before the acute episode and if there was an obvious source. If both of these criteria were absent the nature of the occlusion was classified as unknown(?).

(b) Clearing of Main Artery.-The clearing of the main artery was based not only on arteriographic criteria but also on clinical evaluation. In no case was a contradiction found between the clinical evaluation and the findings on the arteriogram performed after the streptokinase treatment. If the pulse suddenly reappeared the arteriogram always showed patency of the main artery. The following symbols were used for the clinical classification of clearing: $++=$ reappearance of the pulsations in at least one artery of the foot or the hand; $+=$ reappearance of the pulse at a level where it was previously not palpable, but no reappearance in the hand or foot; and $-=$ no reappearance of previously absent pulsations.

(c) Degree of Ischaemia.-The condition of the leg before the start of therapy was graded according to the following criteria, mainly based on neurological signs: grade 1, no neurological abnormalities, perhaps a cold leg; grade 2, hypoaesthesia or ischaemic pain; and grade 3, anaesthesia of at least part of the limb.

(d) Amputation Rate--Evaluation of the amputation was considered not to be possible when only a yes or no score was used. The following score was employed: amputation + means the amputation was performed or the amputation was decided on but not performed in the hospital because the patient had died or had left; amputation-means the amputation was neither performed nor planned-that is, the patient left the hospital without an amputation and an amputation was not considered necessary, or the patient died without an amputation when the need for amputation was ruled out; and, amputation ? means the patient died before it could be decided that an amputation could be avoided.

(e) Mortality Rate.-Only hospital mortality is considered.

\section{Results}

\section{(1) Factors affecting Clearing of Main Artery}

(a) Occlusion Time.-This is defined as the time interval between the onset of the acute symptoms and the start of treatment. In Table I only cases with an occlusion of the iliac, femoral, or popliteal artery who received at least $10^{6}$ units of streptokinase were included. Two cases in fact received less than $10^{6}$ units; in one case the treatment was instituted during half an hour's wait for the surgeon, and in the other the treatment was interrupted after half an hour because of pyrogenic reactions. The frequency of the clearing of iliac, femoral, and popliteal artery occlusions treated with at least $10^{6}$ units of streptokinase increased when the treatment was started early. Using the $\chi^{2}$ test, the frequency of clearing was significantly higher $(\mathrm{P}<0.001)$ in patients treated within 72 hours $(36 / 53)$ than in those treated later $(1 / 14)$. The same tendency was seen when the occlusion was located in another limb artery, whether an embolus or a thrombus occurred.

(b) Nature of Occlusion.-The distinction between embolus and thrombus was made on clinical grounds as already mentioned. To eliminate the possible influence of the occlusion time only patients with a recent occlusion ( $<72$ hours) of the iliac, femoral, or popliteal artery who received at least $10^{6}$ units of streptokinase were considered. The occlusion time was in fact slightly but not significantly longer in the patients with thrombi ( 24 hours) than in those with emboli (16.5 hours), and the clearing ratio was slightly but not significantly lower in patients with thrombi (11/15) compared with cmboli (18/24). Nor was a significant difference found when other locations and patients with other occlusion times were considered.

(c) Site of Occlusion.-In considering the clearing ratio according to the location of the thromboembolic occlusion, patients with both emboli and thrombi were included if they were treated with at least $10^{6}$ units of streptokinase between 12 and 47 hours after the onset of the acute symptoms. The clearing rate of iliac artery obstructions $(10 / 17)$ was similar to that of femoral and popliteal obstructions (8/14), and hence these groups can be considered together. The higher clearing

TABLE I.-Clearing and Occlusion Time

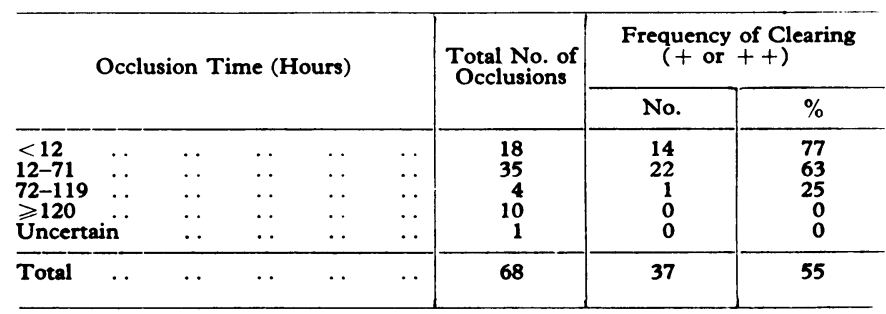


rate in aortic occlusions (4/5) compared with iliac, femoral, and popliteal artery occlusions (18/31), however, were not significant ( $P=0.2$ using the $\chi^{2}$ test).

(d) Degree of Ischaemia.-The condition of the leg before the start of therapy was graded according to the criteria mentioned above. In those patients with iliac, femoral, or popliteal artery occlusions treated with over $10^{6}$ units of streptokinase between 12 and 47 hours after the onset of the acute symptoms, no difference in clearing ratio was found between the three groups; the clearing ratio was indeed $2 / 5$ in the group of patients with a grade I local condition of the leg on admission, $11 / 17$ in group 2 , and $5 / 9$ in group 3 . Nor was a difference in arterial clearing found when the treatment was started early or late.

(e) Dose of Streptokinase.-The clearing ratio was not considered in connexion with the total amount of streptokinase infused. Indeed, if the treatment was successful after, for example, 12 hours it was interrupted, but if unsuccessful it was continued for three days. When correlating the clearing and the initial dose, which was infused in about half an hour as a loading dose, the clearing ratio was higher in patients receiving the lowest initial dose $(9 / 10)$ (Table II). These figures were compiled from patients with iliac, femoral, or popliteal artery occlusion treated with at least $10^{6}$ units of streptokinase, the treatment being started within 12 to 47 hours after onset of the acute symptoms. From a comparison of the group of patients receiving less than $0.5 \times 10^{6}$ with those receiving more, this difference was significant $(\mathrm{P}=0.05$ using the $\chi^{2}$ test); furthermore, the occlusion time, the condition of the leg, and the general condition of the patients were not significantly different in those treated with a high or a low initial dose. These differences are therefore probably related to the different initial dose, though a prospective study would be desirable.

Finally, the clearing ratio was related to the occlusion time and the amount of streptokinase infused as initial dose, and not to the nature of the occlusion. Thus the clearing rate in large arteries is probably higher than in small arteries.

\section{(2) Factors Affecting Amputation Rate}

Excluding the two patients who received less than $10^{6}$ units of streptokinase, and did not undergo amputation, the score for amputation was positive in $26 / 83(31 \%)$ and negative in $38 / 83(46 \%)$.

(a) Occlusion Time.-No relation could be found between the occlusion time and the amputation rate if the same clearing ratio was obtained. This suggests that the apparent relation between the amputation ratio and occlusion time exists only if a different clearing ratio is observed. Possibly therefore the occlusion time does not influence the amputation ratio directly, but only indirectly by its influence on the clearing ratio.

(b) Nature of Occlusion.-No direct relation was found between nature of occlusion and amputation ratio if clearing ratio and local condition of the limb at admission were equal:

(c) Site of Occlusion.- The amputation rate for all patients treated within the first 72 hours who received more than the $10^{6}$ units of streptokinase is given in Table III. Since the amputation ratio was almost identical in iliac, femoral, and popliteal artery occlusions all locations of arterial occlusions are considered together.

(d) Degree of Ischaemia.-In considering the frequency of amputation as a function of clearing of the main artery, only patients with an iliac, femoral, or popliteal artery occlusion treated within 72 hours with more than $10^{6}$ units of streptokinase where the amputation could be evaluated were included.

In all cases where extensive clearing $(++)$ was obtained amputation was neither performed nor planned; the amputation rate was particularly high, however (6/7), when no clearing was observed (Table IV).

(e) Clearance of Main Artery.-If the local condition was grade 1 on admission, amputation was never necessary (0/7), even if no clearing was observed (Table IV); on the other hand, even if it was grade 3, amputation could still be prevented if extensive clearing was observed $(0 / 5)$. If the local condition of the leg is grade 2 the amputation ratio is closely related to the clearing.

(f) Dose of Streptokinase.-As a higher clearing ratio was observed with a lower initial dose, we tried to estimate whether a greater amputation ratio was obtained with a higher initial dose. The high frequency of cases, however, where amputation could not be definitely evaluated (?) does not allow conclusions to be drawn.

Of the different relations examined, only the local condition of the leg on admission and the clearing ratio were related to the amputation ratio; grade 1 condition on admission or an extensive clearing $(++)$ seemed to prevent amputation.

\section{(3) Factors Affecting Mortality Rate}

The total hospital mortality was 30/85 (35.2\%); $16 / 85$ $(18.8 \%$ ) died early (within the first five days) and $14 / 85$ $(16.4 \%)$ died later during the hospital stay, the average stay being three weeks.

(a) General Medical State.-The 85 patients were divided into three groups according to their general condition on admission, the criteria mentioned above being used. Of those admitted in good general condition (grade 1) only one died during the hospital stay (Table V); this patient developed anuria followed by bleeding during coumarin treatment, and eventually died of renal insufficiency. In patients of the same age the relation between mortality and general condition persists; this factor has to be taken into account during further evaluation of the mortality.

(b) Occlusion Time.-This was not related to the hospital mortality.

TABLE II.-Clearing and Streptokinase Dose

\begin{tabular}{|c|c|c|c|c|c|c|c|}
\hline \multicolumn{5}{|c|}{ Initial Dose ( $10^{\circ}$ units) } & \multirow{2}{*}{$\begin{array}{c}\text { Total No. of } \\
\text { Cases }\end{array}$} & \multicolumn{2}{|c|}{ Clearing Rate } \\
\hline & & & & & & + or ++ & - \\
\hline $\begin{array}{l}<0.5 \\
0.5-1.19 . \\
\geqslant 1.2\end{array}$ & $\begin{array}{l}. \\
\cdots\end{array}$ & $\begin{array}{l}\ldots \\
\cdots\end{array}$ & $\begin{array}{l}\ldots \\
\cdots\end{array}$ & $\begin{array}{l}\ldots \\
\cdots\end{array}$ & $\begin{array}{r}10 \\
9 \\
12\end{array}$ & $\begin{array}{l}9 \\
4 \\
5\end{array}$ & $\begin{array}{l}1 \\
5 \\
7\end{array}$ \\
\hline Total & $\ldots$ & $\ldots$ & $\ldots$ & $\ldots$ & 31 & 18 & 13 \\
\hline
\end{tabular}

TABLE III.-Amputation and Location of the Occlusion

\begin{tabular}{|c|c|c|c|c|c|c|c|}
\hline \multirow{2}{*}{\multicolumn{3}{|c|}{ Location (Artery) }} & \multirow{3}{*}{$\begin{array}{c}\begin{array}{c}\text { Total No. } \\
\text { of Cases }\end{array} \\
8 \\
26 \\
27 \\
2 \\
5\end{array}$} & \multicolumn{3}{|c|}{ Amputation } & \multirow{2}{*}{$\mid \begin{array}{c}\text { Occlusion } \\
\text { Time } \\
\text { (Hours) }\end{array}$} \\
\hline & & & & \multirow{2}{*}{$\begin{array}{c}+ \\
0 \\
8 \\
9 \\
1 \\
1\end{array}$} & \multirow[b]{2}{*}{$\begin{array}{r}- \\
3 \\
9 \\
12 \\
1 \\
4\end{array}$} & \multirow{2}{*}{$\begin{array}{l}? \\
5 \\
9 \\
6 \\
0 \\
0\end{array}$} & \\
\hline $\begin{array}{l}\text { Aorta } \\
\text { Iliac . . } \\
\text { Femoral and poplit } \\
\text { Calf . } \\
\text { Upper extremity }\end{array}$ & $\begin{array}{cc}\ldots & \ldots \\
\text { eal } & \text { arteries } \\
\ldots & \ldots \\
\ldots & \ldots\end{array}$ & $\begin{array}{l}\cdots \\
\cdots \\
\cdots \\
\cdots\end{array}$ & & & & & $\begin{array}{r}13 \cdot 5 \\
17.5 \\
19.5 \\
7 \\
13\end{array}$ \\
\hline Total & .. & . & 68 & 19 & 29 & 20 & \\
\hline
\end{tabular}

TABle IV.-Amputation Ratio, Local Situation on Admission and Clearing Ratio

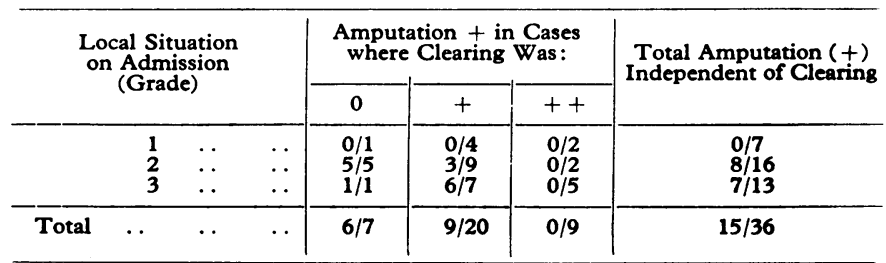


Table V.-Mortality, General Condition on Admission, and Age

\begin{tabular}{|c|c|c|c|c|c|c|}
\hline \multirow{2}{*}{\multicolumn{3}{|c|}{ General Condition (Grade) }} & \multirow{2}{*}{$\begin{array}{l}\text { Total No. } \\
\text { of Patients }\end{array}$} & \multicolumn{2}{|c|}{ Mortality } & \multirow{2}{*}{$\begin{array}{c}\text { Mean Ag } \\
\text { (Years) }\end{array}$} \\
\hline & & & & No. & $\%$ & \\
\hline & $\begin{array}{l}1 \\
2 \\
3\end{array}$ & $\begin{array}{l}\ldots \\
\cdots\end{array}$ & $\begin{array}{l}22 \\
45 \\
18\end{array}$ & $\begin{array}{r}1 \\
14 \\
15\end{array}$ & $\begin{array}{r}4 \cdot 5 \\
31 \cdot 1 \\
83 \cdot 3\end{array}$ & $\begin{array}{l}56 \cdot 7 \\
60 \\
66 \cdot 4\end{array}$ \\
\hline Total . . & & $\ldots$ & 85 & 30 & 35 & \\
\hline
\end{tabular}

TABLE VI.-Mortality and Location of the Occlusion

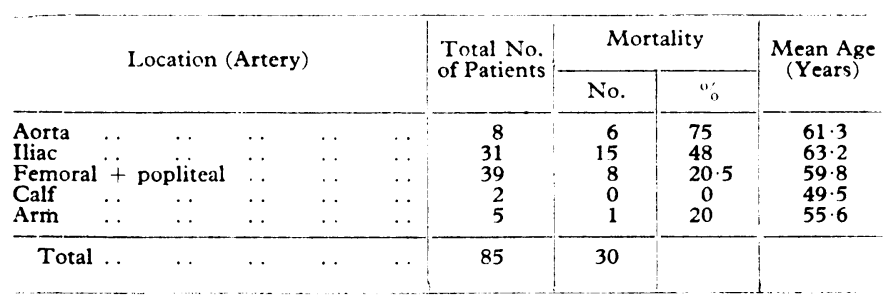

TABLE VII.-Mortality and the Initial Dose of Streptokinase

\begin{tabular}{|c|c|c|c|c|c|c|}
\hline \multirow{2}{*}{$\begin{array}{l}\text { Initial Dose } \\
\text { (10' Units) }\end{array}$} & \multicolumn{2}{|c|}{ Iliac Artery } & \multicolumn{2}{|c|}{$\begin{array}{c}\text { Femoral }+ \\
\text { Popliteal Arteries }\end{array}$} & \multicolumn{2}{|c|}{$\begin{array}{l}\text { Iliac, Femoral } \\
\text { Popliteal Arteries }\end{array}$} \\
\hline & $\begin{array}{l}\text { Total } \\
\text { No. }\end{array}$ & Mortality & $\begin{array}{l}\text { Total } \\
\text { No. }\end{array}$ & Mortality & $\begin{array}{l}\text { Total } \\
\text { No. }\end{array}$ & Mortality \\
\hline $\begin{array}{l}<0.5 \\
0.5-1.19 \\
\geqslant 1.2 \quad \ldots\end{array}$ & $\begin{array}{l}4 \\
7 \\
5\end{array}$ & $\begin{array}{l}0 \\
5 \\
3\end{array}$ & $\begin{array}{r}8 \\
5 \\
10\end{array}$ & $\begin{array}{l}0 \\
1 \\
4 \\
\end{array}$ & $\begin{array}{l}12 \\
12 \\
15\end{array}$ & $\begin{array}{r}0 \\
6 \\
7 \\
\end{array}$ \\
\hline Total & 16 & 8 & 23 & 5 & 39 & 13 \\
\hline
\end{tabular}

(c) Nature of Occlusion.-No relation was found between hospital mortality and the nature of the occlusion.

(d) Site of Occlusion.-The mortality was higher in patients with occlusions of the larger arteries (Table VI). These differences are probably not due to a difference in age of the patients, since the small variations in ages are unlikely to provoke differences in mortality. To evaluate in greater detail the relation between mortality and thrombus location we considered only patients with a general condition of grade 2 . Though the 16 patients in this group with an iliac artery occlusion were not older ( 60.4 years), the mortality rate was higher $(8 / 16)$ than that in patients with an occlusion in the femoral artery (5/23), whose age averaged 61.6 years.

(e) Degree of Ischaemia.-This was not related to hospital mortality when the general condition was taken into account.

(f) Clearance of Main Artery.-This was not related to hospital mortality if the other factors were comparable.

(g) Dose of Streptokinase.-The early mortality (16/85) in six cases was probably due to, or at least precipitated by, the streptokinase infusion; three died of cerebral haemorrhages (one patient had hypertension), one of small-bowel haemorrhage, and two of retroperitoneal haemorrhages (one patient had previously had translumbar aortography). Three of the early deaths were not caused by streptokinase; one patient died of intractable heart failure, one of shock after arteriography, and one of hyperkalaemia and anuria, also after arteriography. Of the remaining seven cases the cause was not clear in five (three of them showed cerebral disturbances before death) and two died after a recent myocardial infarction; the relation between streptokinase treatment and the causes of death in these seven cases was uncertain.

In none of the 14 patients who died later during their stay in hospital was streptokinase the direct cause of death. It should be stressed that nine patients in this group died of a thromboembolic complication-six of myocardial infarction, two of pulmonary emboli, and in one a large clot was found in the left ventricle. The relation between streptokinase treatment and death from thromboembolic complications in the late hospital period was uncertain. No relation was found between the mortality and the total amount of streptokinase given, but if the patient died early the treatment was interrupted and he received only a few million units.

We therefore evaluated the relation between mortality and initial dose of streptokinase (first half-hour) only in patients with a grade 2 general condition on admission with an iliac, femoral, or popliteal artery occlusion. Though the mean age is not different in the three subgroups, the lowest mortality $(0)$ was found in the group receiving less than $0.5 \times 10^{6}$ units of streptokinase as initial dose (Table VII). The difference between this group and the two others together is significant $(0.02>P>0.01)$. In the 15 patients who received an initial dose of $1.2 \times 10^{6}$ units of streptokinase or more, no difference in mortality was found between those who received this initial dose-because a standard dosage was applied (5/11)-and those who received this loading dose after individual titration $(2 / 4)$.

In the 22 patients with a grade 1 general condition and the same occlusion sites, a hospital mortality of $1 / 11$ occurred in those receiving $1.2 \times 10^{6}$ units or more; neither of the two patients receiving less than $0.5 \times 10^{6}$ units died nor did any of the eight receiving an initial dose between $0.5 \times 10^{6}$ and $1.2 \times 10^{6}$ units. In patients with grade 3 general condition the number who did not die was too low in each class to permit definite conclusions, but the same trend was seen.

Thus no relation was found between the mortality and the nature of the thromboembolic artery occlusion. When considering patients with a medium general condition, the mortality was higher in those receiving more than $0.5 \times 10^{6}$ units of streptokinase as initial dose than in those receiving less streptokinase. This difference was not due to the patient's general condition on admission or the location of the occlusion.

\section{(4) Overall Success Rate}

Successful treatment is defined as (1) when a patient can leave hospital without amputation, (2) if the arterial pulsations reappear and remain present until discharge at least at one level below the occlusion site, and (3) when no serious complications occur. The atherosclerotic disease, however, which was often the cause of the occlusion, remains unaltered. The reappearance of pulsations at only one level distal from the occlusion was used as a criterion, since many patients already had the more distal artery occluded.

Only patients in whom treatment was started within the first 72 hours after the onset of the acute symptoms and who received more than $10^{6}$ units of streptokinase were considered. The overall success rate was $21 / 68$, being slightly but not significantly higher in small-artery occlusions and lower in largeartery occlusions. Thus the overall success rate is higher when clearing occurs than when clearing fails. All patients who had complications, even those not related to streptokinase administration, were classified as having had an unsuccessful treatment.

\section{(5) Complications of Treatment}

Side effects during streptokinase therapy were frequent, and are described below.

(a) Bleeding Complications.-Besides small ecchymoses, bleeding occurred in $16 / 85$ patients and was probably the cause of death in six. In a further six patients bleeding occurred around catheters or at puncture sites. Furthermore, each of the following complications were noticed once: bleeding at operation site, epistaxis, haemoptysis, important ecchymoses. No definite relation was found between the dose of streptokinase and the bleeding complications, as observed in this series.

(b) Psychological Upsets.-Psychological upsets without 
neurological signs were seen in $14 / 85$ patients and were characterized by hallucinations in two, agitation in three, confusion in six, and decrease in consciousness in three. Of these 14 patients, nine survived and five died: two in the late hospital period from a myocardial infarction, three in the early period from an unknown cause.

(c) Chills and Temperature Rise.-Chills or a rise in temperature above $38^{\circ} 5 \mathrm{C}$. were observed in eight cases. In one case treatment was interrupted because of the chill. In the other seven cases it was unnecessary to interrupt the treatment; in fact these seven patients died. In none of the cases could a direct relationship between the streptokinase treatment and the cause of death be found.

(d) Shock.-This occurred in three instances (3/85) but none of the patients died. In each case the shock was caused by streptokinase, twice because of bleeding and once because of chills.

(e) Renal Insufficiency.-This occurred four times-two patien:s died and two survived. Three underwent arteriography, and this procedure was probably the precipitating cause of the renal shut down.

(f) Acute Cerebrovascular Accident.-Five patients had an acute cerebrovascular accident during streptokinase administration. The three patients with a cerebral haemorrhage died early. In two cases the accident was due to a cerebral embolus-one patient survived and one died during the later stages of a pulmonary embolus.

(g) Thromboembolic Complications.-Eight patients developed thromboembolic complications during streptokinase administration; of these, two had cerebrovascular accidents; one deep phlebitis in the calf, without further complications; two pulmonary emboli, one patient dying and one surviving; and three myocardial infarctions, of whom all three died.

Thus complications during stay in hospital were frequent. The causal relationship between these complications and the streptokinase treatment, however, could not always be established.

\section{Discussion}

Our findings were based on a retrospective review and not a planned, controlled, and randomized study; the results should therefore be interpreted with caution. To our knowledge no controlled study on the subject is available. Our results may therefore be compared with other reports and especially that of Hess (1967), who compiled data on streptokinase treatment in 245 instances of emboli and 193 of thrombi in different European centres, including ours.

In patients treated within the first week after the thromboembolic occlusion of the limb arteries we found a higher frequency of clearing in those treated within 72 hours than those treated later. The same tendency was seen by Hess (1967). This, however, does not prove that the higher clearing rate in more recent occlusions was due only to the early treatment, as patients were not allocated at random to an early or late treatment group. The figures, however, favour early treatment. Furthermore, present data do not exclude the possibility that clearing could be obtained in patients treated several months after the acute episode, since no such cases were included. More recent data published by Schoop et al. (1968) and Poliwoda et al. (1969) do indeed prove that clearing can occur under these conditions.

Though we did not find a clear relationship between the clearing rate and the nature of the occlusion, Hess (1967) has shown that complete lysis occurred more frequently in patients with emboli ( $55 \%$ ) than in those with thrombosis $(34 \%)$; this difference is highly significant $(P<0.001)$. The difference persists when patients with the same occlusion time before the start of therapy are compared. In the review by Hess (1967) patients in whom the differential diagnosis between thrombosis and embolism could not be made were allocated to the thrombosis group. When the same procedure was applied to our results a similar tendency was seen, but was not sufficiently significant $(P>0 \cdot 1)$.

In our study no significant relation was found between the location of the occlusion and the clearing. Hess (1967), however, found the highest clearing ratio in occlusions of the arms $(82 \%$ in the axillary artery); in the legs the clearing ratio increased significantly $(\mathrm{P}=0.002)$ from the aorta $(12 \%)$ down to the popliteal artery $(61 \%)$; in the latter appraisal the duration of the vascular occlusion was not taken into account.

We also found that in seven patients whose ischaemic leg did not show neurological abnormalities on admission, amputation was never necessary even if clearing was not or only partially obtained (Table IV). The outcome of a similar group of patients treated without streptokinase was not studied here. Furthermore, out of 20 patients in whom clearing at the occlusion site was obtained and even confirmed by arteriography but the pulse did not reappear in at least one of the foot or hand arteries, amputation was necessary in nine. On the other hand, in the nine patients in whom at least one of the distal artery pulsations reappeared the limb was not amputated, even if complete sensory loss of at least part of the limb was present on admission.

Streptokinase was administered according to different dosage schemes in the group of patients reviewed by Hess (1967), but these differences were not taken into account. In our study a significantly lower clearing rate (Table II) and significantly higher hospital mortality rate (Table VII) were found in patients with iliac, femoral, or popliteal artery occlusions receiving an initial dose of more than $0.5 \times 10^{6}$ units of streptokinase compared with those receiving less. This difference was not related to other factors affecting mortality such as the general condition of the patient on admission and location of the occlusion. Even though this is a retrospective review, a difference in hospital mortality is sufficiently impor:ant to modify treatment policy; these findings lead therefore to the recommendation that the previously proposed high standard initial dose of streptokinase should not be used any more (Verstraete et al., 1966).

Furthermore, in a similar group of patients treated with streptokinase according to their individually titrated initial dose, the hospital mortality was significantly higher in the group where the initial dose was $0.5 \times 10^{6}$ units of streptokinase or more $(8 / 15)$ than in the group where a lower initial dose was given $(0 / 10)$. Whatever the result of the titration on an individual patient, an initial dose in excess of $0.5 \times 10^{6}$ units seems to be dangerous. For the same group of patients the hospital mortality was not significantly different in the group treated with a high standard initial dose of $1.2 \times 10^{6}$ units $(5 / 11)$ and the group treated according to their individually titrated initial dose $(8 / 25)$. This could explain why the potential danger of a high standard initial dose was not realized until recently. Moreover, in a single blind randomized multicentre trial comparing heparin and streptokinase treatment (the initial dose being $1.2 \times 10^{6}$ units of streptokinase) in patients with a recent myocardial infarction, a slightly but not significantly higher hospital mortality was seen in the streptokinase (20/83) group compared with the heparin (15/84) group (Amery et al., 1969). On the other hand, in trials on the same disease where a lower initial dose of streptokinase was used a difference in favour of streptokinase was reported (Remy et al., 1966; Hiemeyer et al., 1969).

Amputation rate, hospital mortality, and complications other than embolism or bleeding were not considered in the review by Hess (1967). Embolic complications were reported as the cause of death during streptokinase therapy in $2.3 \%$ (3.2\% in patients treated for embolic occlusions and $1.5 \%$ in thrombotic occlusions). Bleeding was thought to be the cause of death in 23 out of 458 patients $(4.9 \%)$; in seven of them cerebral haemorrhage was probably the cause. Furthermore, 
non-fatal bleeding was reported in $4.1 \%$.

The higher complication rate in our study could be due to other criteria for evaluating the complication rate, to complications related at least partly to the frequent use of arteriography, to the bad general condition of most of our patients on admission, or to the use of a rather high initial dose of streptokinase.

Since the introduction of Fogarty's catheter (Fogarty et al., 1963) the possibilities of vascular surgery have been extended, and this method represents an important alternative for the treatment of patients having the condition under study. An attempt has therefore been made to review published work with the purpose of comparing streptokinase treatment, modern medical therapy, and vascular surgery in patients with recent thromboembolic occlusions of the limb arteries (Amery, 1969).

Streptokinase was kindly supplied by Kabi AB, Stockholm.

\section{REFERENCES}

Amery, A. (1969). Activation of the Human Plasma Fibrinolytic System by Streptokinase, Thesis, Acco-Louvain, Belgium.

Amery, A., Maes, H., Vermylen, J., and Verstraete, M. (1963). Thrombosis et Diathesis Haemorrhagica, 9, 175 .

Amery, A., Roeber, G., Vermeulen, H. J., and Verstraete, M. (1969). Acta Medica Scandinavica, Suppl. No. 505

Cotton, L. T., Flute, P. T., and Tsapogas, M. J. C. (1962). Lancet, 2, 1081.

Fletcher, A. P., Alkjaersig, N., and Sherry, S. (1959). Journal of Clinical Investigation, 38, 1096 .
Fogarty, T. J., Cranley, J. J., Krause, R. J., Strasser, E. S., and Hafner, C. D. (1963). Surgery, Gynecology and Obstetrics, 116, 241 .

Gross, R., Hartl, W., Kloss, G., and Rahn, B. (1960). Deutsche medizinische Wochenschrift, 85, 2129.

Haan, D., and Tilsner, U. (1965). Münchener medizinische Wochenschrift, 107,638 .

Hess, H. (1967). Arterielle Embolien und Thrombosen. Stuttgart, Schattauer. Hiemeyer, V., Rasche, H., and Diehl, K. (1969). Klinische Wochenschrift, 47,371 .

Kahn, P., Stacher, A., and Deutsch, E. (1961). Wiener klinische Wochenschrift, 73, 677 .

McNicol, G. P., Reid, W., Bain, W. H., and Douglas, A. S. (1963). British Medical fournal, 1, 1508 .

Marchal, G., et al. (1964). Archives des Maladies du Coeur et des Vaisseaux, $57,753$.

Nilsson, I. M., and Olow, B. (1962). Acta Chirurgica Scardinavica, 123, 247.

Poliwoda, H., Alexander, K., Buhl, V., Holstein, D., and Wagner, H. H. (1969). New England fournal of Medicine, 280, 689 .

Remy, D., and Gebauer, D. (1966) Medizinische Klinik, 61, 220.

Salmon, J., Lambert, P. H., and Delvigne, J. (1963). Acta Cardiologica, 18, 254.

Schmutzler, R. (1963). Helvetica Medica Acta, 30, 608.

Schmutzler, R. (1968). Angiologica, 5, 119

Schoop, W., Martin, M., and Zeitler, E. (1968). Deutsche medizinische Wochenschrif:, 93, 2321.

Verstraete, M., Amery, A., and Vermylen, J. (1963). British Medical fournal, 1,1499 .

Verstraete, M., Vermylen, J., Amery, A., and Vermylen, C. (1966). British Medical fournal, 1, 454 .

Verstraete, M., Vermylen, J., De Vreker, R., Amery, A., and Vermylen, C. (1964). Scandinavican fournal of Clinical and Laboratory Investigation, 16, Suppl. No. 78, p. 15.

Winckelmann, G., Hiemeyer, V., Weissleder, H., and Schoop, W. (1963). Deutsche medizinische Wochenschrift, 88, 2331.

\title{
Folic Acid in Folate-deficient Patients with Epilepsy
}

\author{
RICHARD H. E. GRANT,* M.B., B.S., D.C.H. ; OLGA P. R. STORES, $†$ м.в., СH.в.
}

\begin{abstract}
ummary: A double-blind trial using folic acid $15 \mathrm{mg}$. daily and identical placebo was carried out in 51 epileptic patients having a serum folate level below $3.6 \mathrm{ng} . /$ $\mathrm{ml}$. Treatment was for a minimum of six months and in 41 patients was for more than one year. There were no significant changes in the frequency of seizures, behaviour, ind personality, or in a number of cognitive functions.
\end{abstract}

\section{Introduction}

Treatment with certain anticonvulsant drugs, especially phenytoin, produces folate deficiency in a high proportion of patients, estimates varying from about 30 to $80 \%$ (Klipstein, 1964; Reynolds et al., 1966a, 1966b). Megaloblastic anaemia is the most obvious manifestation of this deficiency but it is rare, though a megaloblastic bone marrow may be found in nearly $40 \%$ of treated epileptic patients (Reynolds et al., 1966b) and macrocytosis in the peripheral blood in between 11 and 53\% (Reynolds, 1968). Phenytoin inhibits folate absorption from folate polyglutamates, a major component of food folate, and possibly folate deficiency is at least partly due to inhibition of intestinal absorption of folates in the diet (Hoffbrand and Necheles, 1968; Rosenberg et al., 1968).

The clinical consequences of drug-induced folate deficiency have been described by Reynolds (1968, 1970). These include apathy and retardation, loss of concentration and self-confidence, schizophrenic-like psychoses, dementia, and possibly cerebellar or spinal cord damage. If the folate deficiency is corrected by treatment with folic acid the mental state may improve, but at the same time the frequency or severity of

* Director, David Lewis Colony, Alderley Edge, Cheshire.

t Registrar, David Lewis Colony, Alderley Edge, Cheshire. fits has been reported to increase in a significant proportion of patients. Reynolds (1967) studied 26 chronic epileptic patients with folic acid deficiency. Folic acid improved the mental state, but the frequency or severity of fits was increased, necessitating cessation of treatment in ninc patients. Other reports include the case of a man of 43 with megaloblastic anaemia due to phenobarbitone in whom administration of folic aicd rapidly precipitated status epilepticus on two occasions (Chanarin et al., 1960) and a case reported by Wells (1968) in which the patient died in uncontrolled status epilepticus. Dennis and Taylor (1969) described their experience with 5-mg. tablets of folic acid in children with epilepsy as "alarming" but gave no clinical details. Lanzkowsky et al. (1969) studied an 18-year-old girl with an isolated defect of folic acid absorption associated with mental retardation and cerebral calcification who developed epilepsy. They reported that fits decreased in frequency during folatc depletion and increased on folic acid administration, but the degree of change was not stated.

Our clinical impression and that of our colleague, Dr. Neil Gordon (1968), was that folic acid had little observable effect on either the incidence of seizures or behavioural aspects. This impression was gained both from patients and from children attending the outpatient department. It was therefore decided to carry out a controlled clinical trial to assess a number of values in our patients.

\section{Methods}

Preliminary screening of serum folic acid levels in inpatients was carried out, and 51 patients whose serum folate level was less than $3.6 \mathrm{ng} . / \mathrm{ml}$. were selected for study, this level being the lower limit for the laboratory concerned. Of 